\title{
AN EXPERIMENTAL INVESTIGATION OF THE STRESS-STRAIN BEHAVIOUR OF GEOPOLYMER CONCRETE
}

\author{
M. VENU ${ }^{1}$, T. D. GUNNESWARA RAO ${ }^{1 *}$
}

\section{Abstract}

This paper focuses on the mechanical properties and modulus of elasticity of fly ash and GGBS based geopolymer concrete. In this study an 8 molarity concentration of $\mathrm{NaOH}$ and alkaline liquid ratio in a ratio of 2.5 was used. This study includes the stressstrain behaviour along with the flexural strength, compressive strength and split tensile strengths for the GPC20, GPC40 and GPC60 grades. Tests were carried out on $150 \mathrm{~mm} \times 150 \mathrm{~mm} \times$ $150 \mathrm{~mm}$ cubes and $100 \times 100 \times 500 \mathrm{~mm}$ prisms and $150 \times 300 \mathrm{~mm}$ cylindrical geopolymer concrete specimens. The test results noted the good mechanical properties and measured stress-strain relations of fly ash and GGBS based geopolymer concrete under ambient curing conditions. The elastic modulus was significantly varied with increases in the grade of the concrete. An equation was proposed to determine the modulus of elasticity based on the compressive strength of the geopolymer concrete.

\section{Address}

1 Department of Civil Engineering, National Institute of Technology, Warangal, India

* Corresponding author: tdgtdg@gmail.com

\section{Key words}

- Geopolymer concrete,

- Modulus of elasticity,

- Alkaline solution

- Stress-strain.

\section{INTRODUCTION}

One of the major problems with the cement industry is the production of ordinary Portland cement (OPC) as it liberates a huge amount of $\mathrm{CO}_{2}$ into the atmosphere. Attempts have been made to produce alternatives to cement such as cement-free concrete. In which cement is replaced with Ground Granulated Blast Furnace Slag (GGBS) and fly ash which are by-products obtained from the iron and coal industries. Generally, cement-free concrete is made from waste materials such as fly ash and GGBS with an alkaline solution; it is basically a combination of sodium hydroxide $(\mathrm{NaOH})$ and sodium silicate $\left(\mathrm{Na}_{2} \mathrm{SiO}_{3}\right)$, which is a polymerisation process that differs from OPC concrete. Fly ash is rich in alumina and silica, whereas GGBS contains calcium in addition to silica and alumina and possesses pozzolanic properties that makes it suitable material for geopolymer concrete (GPC). The silica, alumina and calcium react with an alkaline activator solution to form the alumino silicate hydrate gel and calcium silicate hydrate (C-S-H) gel responsible for binding. Thus the binder (fly ash and GGBS), alkali liquids, and aggregates are the core components of cement-free concrete. Geopolymers are commonly reported to be much more sustainable than OPC in terms of the reduced production of energy, and lower $\mathrm{CO}_{2}$ is released in comparison with OPC concrete (Turner, 2013). But the use of OPC to produce concrete releases an enormous amount of $\mathrm{CO}_{2}$, which results in pollution of the environment. Also, the production of OPC leads to the depletion of raw materials. To reduce these problems caused by OPC concrete, geo-polymer concrete (GPC) has been introduced; it completely eliminates cement with by-products from thermal power plants and the steel industry. Therefore, the complete replacement of OPC with GGBFS or fly ash or a combination of both would significantly reduce $\mathrm{CO}_{2}$ emissions. Fly ash and GGBS can be used as binders and are suitable materials for the polymerization process. An alkaline activator solution is used as a liquid medium in geopolymer concrete similar to the water in Portland cement concrete. The physical, mechanical and durability properties of GPC depend on the proportion of fly ash and GGBS and the curing process (Duxson, 2007). GPC specimens are either ambient cured or oven. Oven curing at high temperatures of around $60^{\circ} \mathrm{C}-90^{\circ} \mathrm{C}$ enhances the po- 
lymerization process and results in better gel formation, thus leading to improved strength and durability properties (Hardjito, 2004), but it is practically difficult to do under in-situ conditions. To dispense with curing, fly ash is partially replaced with GGBS, which results in high early strength and improved mechanical and durability properties (Davidovits, 2005). It has been reported by various authors that GPC has comparable mechanical properties to those of OPC concrete. It has also been reported that the stress strain behaviour of fly ash and GGBFS-based geopolymer concrete under compression is similar to that of OPC concrete, and it has further been stated that the Poisson's ratio for GPC falls between $0.2-0.24$ (Khadiraniakar et al. 2014; Venu and Rao, 2017). Giasuddin proposed a model for the stress-strain behaviour of geopolymer concrete under a tri-axial state of stress and concluded that the proposed GPC model has many similarities to OPC concrete and that there is an increased stiffness of GPC versus that of OPC concrete (Giasuddin et al. 2014).

The modulus elasticity of fly ash and GGBS-based geopolymer concrete was found to be $25 \%$ to $30 \%$ less than that of OPC concrete (Nath et al., 2017). An equation was proposed to find the modulus of elasticity of fly ash and GGBS-based polymer concrete: $\mathbf{E}_{\text {GPC }=} \mathbf{- 1 1 4 0 0}+\mathbf{4 7 1 2}{\sqrt{f_{\mathbf{c m}}}},\left(f_{\mathrm{cm}}\right.$ is the average compressive strength at 28 days) which was used to compare GPC and OPC concrete to conclude that GPC had a lower modulus of elasticity than OPC concrete (Noushini et al., 2016). The empirical formulae to determine the modulus elasticity of GPC was given based on ACI 318 and concluded that even with an increase in the compressive strength of GPC, there is no significant increase in the modulus of elasticity (R.J. Thomas et al., 2015).

\section{SIGNIFICANCE OF RESEARCH}

Fly ash and GGBS-based geopolymer concrete has attracted attention due to its use of an oven curing technique. Not much literature is available on ambient curing techniques for fly ash and GGBSbased GPC. It has been concluded from the literature that GPC has comparable mechanical properties to that of OPC concrete, but not much literature is available on the modulus of elasticity of GPC under ambient curing. This study examines the performance of geopolymer concrete and aims to determine the modulus of elasticity of GPC20, GPC40 and GPC60 with a combination of fly ash and GGBS as a binder under ambient curing. A comprehensive assessment of their mechanical properties has been evaluated for making geopolymer concrete.

\subsection{Materials}

\section{Binder used}

Fly ash obtained from the NTPC Ramagundam Thermal Power Station, India, and GGBS obtained from Toshali Cements, Vizag, India, were used in this research; their chemical composition is shown in Table 1. Fly ash and GGBS have a specific gravity of 2.17 and 2.9 respectively.

Tab. 1 Chemical composition of Fly ash and GGBS.

\begin{tabular}{ccccccccc}
\hline Composition & $\mathrm{SiO}_{2}$ & $\mathrm{Al}_{2} \mathrm{O}_{3}$ & $\mathrm{Fe}_{2} \mathrm{O}_{3}$ & $\mathrm{SO}_{3}$ & $\mathrm{CaO}$ & $\mathrm{MgO}$ & $\mathrm{Na}_{2} \mathrm{O}$ & LOI \\
\hline Fly ash & 60.11 & 26.53 & 4.25 & 0.35 & 4.00 & 1.25 & 0.22 & 0.88 \\
GGBS & 34.06 & 20 & 0.8 & 0.9 & 32.6 & 7.89 & NIL & NIL \\
\hline
\end{tabular}

\section{Aggregate}

River sand was used as a fine aggregate (FA) and corresponds to Zone-II of IS 383:1978. Crushed rock was used as a coarse aggregate (CA). The fine aggregate and coarse aggregate have a specific gravity of 2.58 and 2.7 with fineness moduli of 2.7 and 6.36 respectively.

\section{Alkaline Activator Solution}

A combination of sodium silicate and sodium hydroxide in a mass ratio of 2.5 was used as an alkaline activator solution. $\mathrm{NaOH}$ in a pellet form and $\mathrm{Na}_{2} \mathrm{SiO}_{3}$ in a liquid form was obtained from Finar Chemicals, India. An $\mathrm{NaOH}$ solution with a concentration of $8 \mathrm{M}$ was used. The sodium silicate solution with a chemical composition of $\mathrm{Na}_{2} \mathrm{O}=8.5 \%, \mathrm{SiO}_{2}=26.5 \%, \mathrm{H}_{2} \mathrm{O}=65 \%$ by mass was used. The alkaline activator solution has a $\mathrm{Na}_{2} \mathrm{O} / \mathrm{SiO}_{2}$ (molar ratio) of 0.6. For proper mixing of the solutions, it has been suggested to prepare the alkaline activator solution one day prior to the casting.

\section{Superplasticizer (SP)}

A sulphonated naphthalene-based high range water reducer, i.e., CONPLAST SP 430, which was obtained from Fosroc Chemicals, India, was used as a superplasticizer (SP) to improve the workability of the mix. The dosage of superplasticizer (SP) mentioned in Table 2 is with respect to the weight of the binder (fly ash and GGBS).

\section{EXPERIMENTAL PROGRAM}

The experimental program consisted of determining the fresh and hardened properties of fly ash and GGBS-based geopolymer concrete cured under ambient conditions. The mechanical properties and modulus of elasticity were determined for GPC20, GPC40 andGPC60. The modulus of elasticity was determined on cylinder specimens $150 \mathrm{~mm}$ diameter cylinder specimens with a $300 \mathrm{~mm}$ height. For each mix 3 cubes sized $150 \mathrm{~mm}$ x $150 \mathrm{~mm}$ x $150 \mathrm{~mm}, 6$ cylinders sized $150 \mathrm{~mm}$ diameter $\times 300 \mathrm{~mm}$ height, and 3 prisms sized $100 \mathrm{~mm} \times$ $100 \mathrm{~mm} \times 500 \mathrm{~mm}$ were cast to determine their modulus of elasticity and their corresponding mechanical properties. The mix proportions for the GPC20, GPC40 and GPC60 are shown in Table 2. The following mix proportions are adopted from the literature (Rao GM and Rao TDG, 2016).

Tab. 2 Mix Proportions of the Geopolymer Concrete.

\begin{tabular}{|c|c|c|c|c|c|c|c|c|}
\hline Mix & Fly ash & GGBS & $\begin{array}{l}\text { Fine } \\
\text { Agg. }\end{array}$ & $\begin{array}{c}\text { Coarse } \\
\text { Agg. }\end{array}$ & $\begin{array}{l}\text { Alkaline } \\
\text { Soln }\end{array}$ & $\mathrm{Na}_{2} \mathrm{SiO}_{3}$ & $\mathrm{NaOH}$ & $\begin{array}{l}\text { SP } \\
(\%)\end{array}$ \\
\hline GPC20 & 252 & 108 & 774 & 1090.8 & 198 & 141.42 & 56.57 & 3 \\
\hline GPC40 & 270 & 180 & 760 & 972 & 248 & 177.15 & 70.85 & 4 \\
\hline GPC60 & 260 & 260 & 717.6 & 915.2 & 286 & 204.28 & 81.72 & 5 \\
\hline
\end{tabular}

All units are in $\mathrm{kg} / \mathrm{m}^{3}$

\subsection{Preparation of the GPC specimens}

The concrete ingredients were weight batched according to the mix proportions given in Table 2. Initially, the coarse and fine aggregates were dry mixed in a Hobart mixer for 3 minutes. Then the 


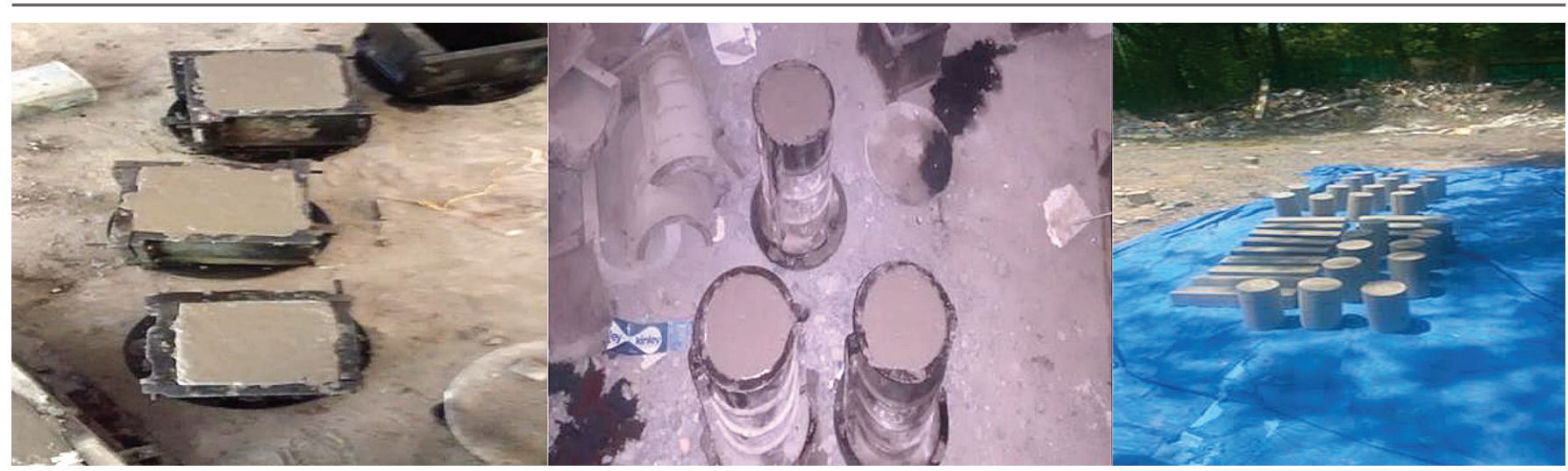

Fig. 1 Casting and curing of GPC specimens.

binder (fly ash and GGBS) was added to the aggregates and mixed for about 3 minutes; the prepared alkaline solution was added along with the super plasticizer, if any. The mixing continued for about 4 minutes until a homogeneous mixture was obtained. Before casting the specimens, the workability of the GPC in terms of slump was measured. These 3 cubes, 6 cylinders, and 3 prisms were cast simultaneously. The specimens were demoulded after one day and cured under direct sunlight until the testing day (28 days). The casting and curing of the specimens is shown in Figure 1. The mix proportions and slump values are given in Table 3 .

\subsection{Testing of the GPC Specimens}

The modulus of elasticity of the GPC was measured from the stress-strain curve as a ratio of the stress to the strain up to the elastic limit (the secant modulus). The tests were performed according to IS: 516-1959. All the prepared cylinder specimens were connected to an extensometer for recording any deformations at the corresponding loads. The tests were performed using a Tinius-Olsen testing machine with a $2000 \mathrm{kN}$ capacity. The test set up is shown in Figure 2. The modulus of elasticity for the geopolymer cylindrical specimen was determined according to the procedure specified in ASTM standard C469-02. The following equation was used to estimate the elastic modulus of the geopolymer cylindrical specimen (Giasuddin, 2014).

$$
\mathrm{E}_{\mathrm{c}}=1450\left(\mathrm{f}_{\mathrm{c}}^{1}\right)^{1 / 2} \quad \mathrm{f}_{\mathrm{c}}{ }^{1}=\text { Peak axial stress in MPa }
$$

For each mix, i.e., the GPC20, GPC40 and GPC60, three (3) cylinders were tested for the elastic modulus; then, the corresponding compressive, split tensile and flexural strengths were found (IS: 516). The setup for the flexural strength, compressive and split tensile tests are shown in Figures 3, 4, and 5.

\section{RESULTS AND DISCUSSION}

\subsection{Workability of GPC}

The workability of the geopolymer concrete for the different mixes is shown in Table 3.

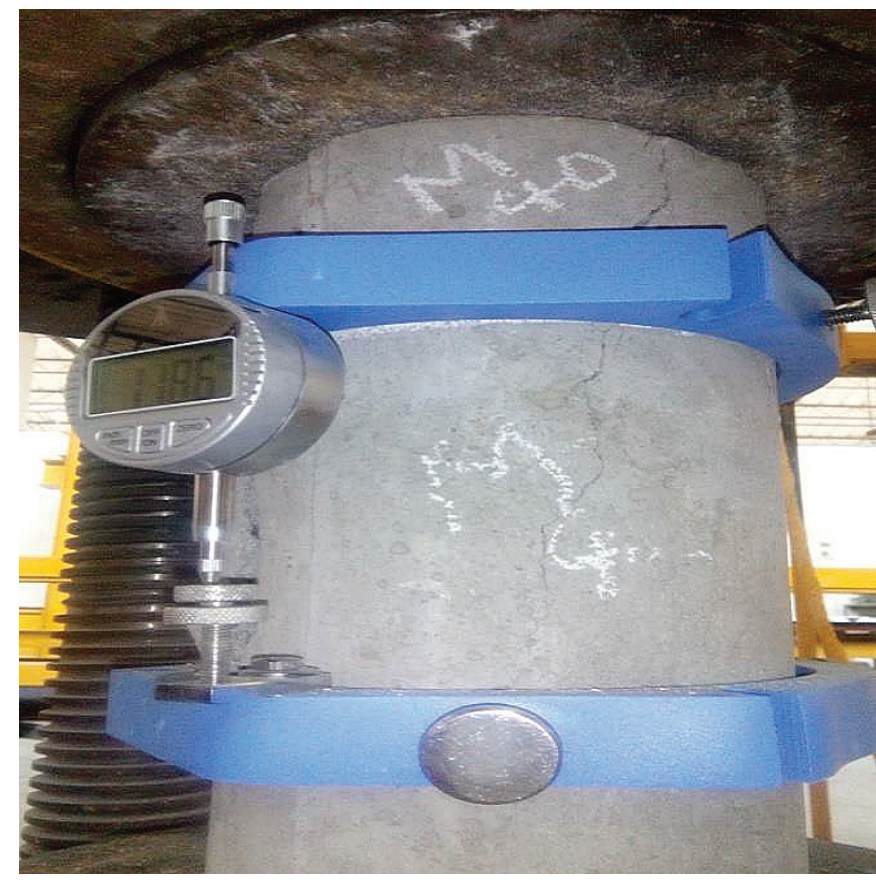

Fig. 2 Test setup for Elastic Modulus.

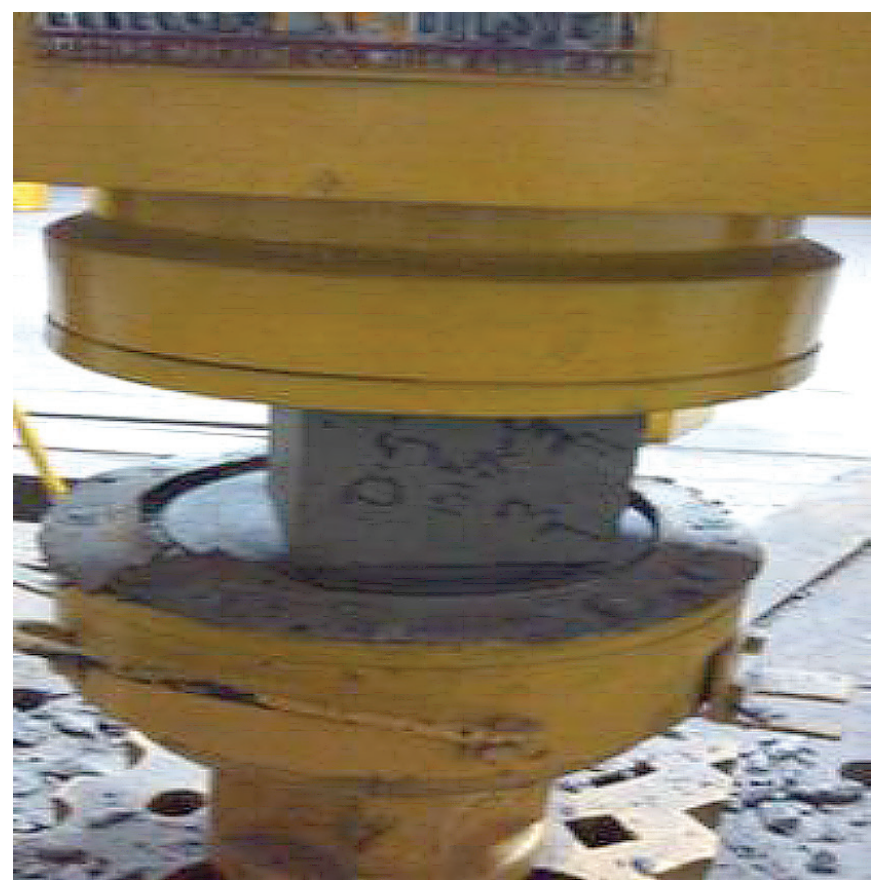

Fig. 3 Compressive Strength of Cube. 


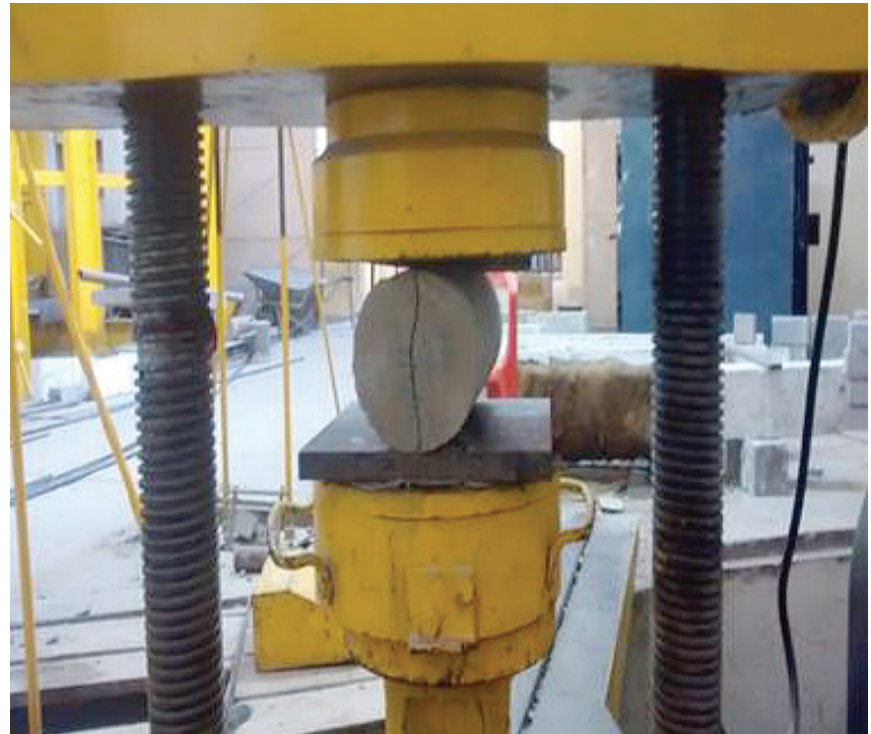

Fig. 4 Test Setup for Split Tensile test.

Tab. 3 Workability of GPC.

\begin{tabular}{ccc}
\hline GPC Mix & $\begin{array}{c}\text { Mix Proportion } \\
\text { (Binder: FA: CA: Alkaline soln.) }\end{array}$ & Slump (mm) \\
\hline GPC20 & $1: 2.15: 3.05: 0.55$ & 122 \\
GPC40 & $1: 1.69: 2.16: 0.5$ & 110 \\
GPC60 & $1: 1.38: 1.76: 0.5$ & 78 \\
\hline
\end{tabular}

According to Table 3, we can conclude that the GGBS content is indirectly proportional to its workability. This might be due to faster polymerization at a higher GGBS content, which results in decreased workability.

\subsection{Mechanical properties of GPC}

The compressive, flexural and split tensile strengths were determined after 28 days of curing, and the results obtained are shown in Table 4. The values in Table 4 are the averages of the three specimens.

Tab. 4 Mechanical Properties of GPC.

\begin{tabular}{ccccc}
\hline Mix & $\begin{array}{c}\text { Binder } \\
\text { Content } \\
\left(\mathrm{kg} / \mathrm{m}^{3}\right)\end{array}$ & $\begin{array}{c}\text { Compressive } \\
\text { Strength } \\
(\mathrm{MPa})\end{array}$ & $\begin{array}{c}\text { Split Tensile } \\
\text { Strength } \\
(\mathrm{MPa})\end{array}$ & $\begin{array}{c}\text { Flexural } \\
\text { Strength } \\
(\mathrm{MPa})\end{array}$ \\
\hline GPC20 & 360 & 26.76 & 2.16 & 2.2 \\
GPC40 & 450 & 43.44 & 3.73 & 3.61 \\
GPC60 & 520 & 62.89 & 5.49 & 5.36 \\
\hline
\end{tabular}

For the compressive strength of $20 \mathrm{MPa}$ (GPC20), the fly ash and GGBS proportions were selected in a ratio of 70:30. For the GPC40 and GPC60, the fly ash and GGBS proportions were 60:40 and 50:50 respectively. As seen in Table 4, the increase in compressive strength is due to the increase in the binder content and the increase in the GGBS content. With a higher binder content, a greater amount of alkaline solution is available for polymerization, which results in the increased strength of the concrete. With a higher GGBS content more calcium is available for polymerization, which results in the

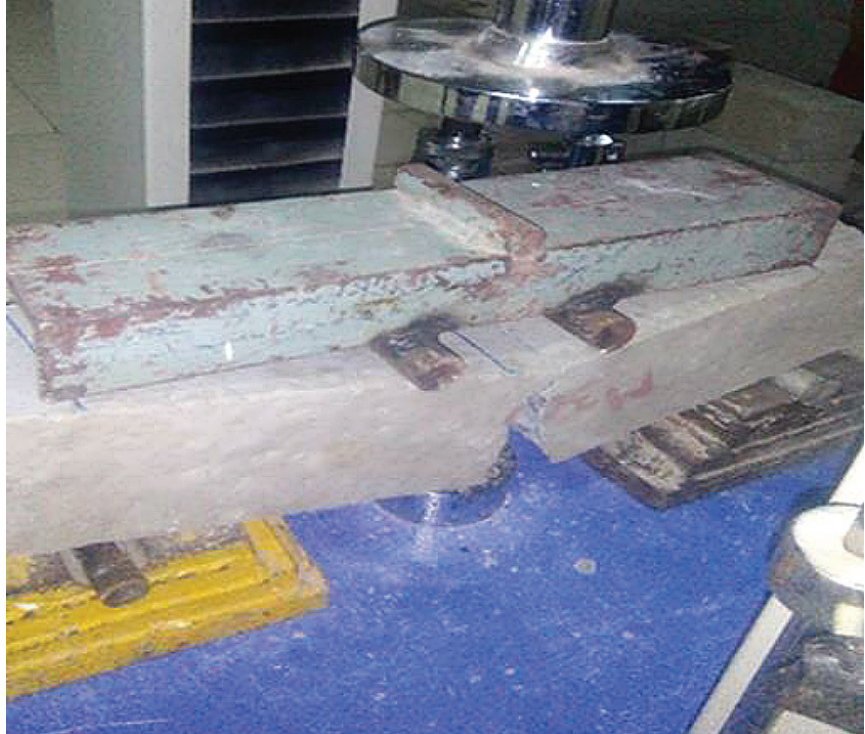

Fig. 5 Test Setup for Flexural Strength.

formation of additional C-A-S-H gel along with N-A-S-H gel, there by leading to an enhancement in strength.

Split tensile and flexural strength tests are normally carried out to evaluate the tensile strength of concrete. The flexural strength of the GPC specimens was determined under two point loading with the longitudinal axes perpendicular to the loads. The split tensile and flexural strengths of the GPC specimens cured under ambient conditions are shown in Table 4. The results concluded that with an increase in the slag content, the split tensile and flexural strength of the GPC increases. The rate of development of the tensile strength increased considerably with the inclusion of GGBS in the binder. The reaction of the slag is higher compared to that of fly ash, thereby resulting in a higher strength (Puertas, 2000).

With the increase in the compressive strength of the GPC, its corresponding split tensile and flexural strength is seen to increase in a similar manner. The results obtained indicated that the GPC mixes with GGBS and fly ash as a binder indicate good mechanical properties under ambient curing conditions without the need for heat curing as in the case of fly ash-based geopolymer concrete. Our findings are in agreement with (Siddique, 2007).

\subsection{Modulus of Elasticity of the GPC}

The stress-strain curve of the GPC specimens tested under compression is shown in Figure 6, and the modulus of elasticity results are shown in Table 5 .

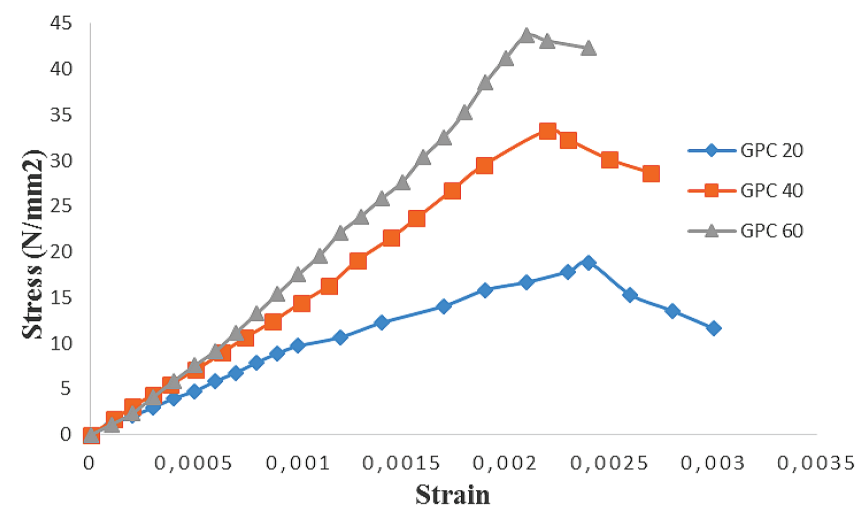

Fig. 6 Stress-Strain Curve of the GPC. 
Figure 6 shows that the ultimate stress increased with the increase in the compressive strength of the concrete. The maximum strain is found to decrease with an increase in the compressive strength. GPC20 is more ductile than GPC40 and GPC60. A similar trend was observed in the stress-strain behaviour for the GPC40 and GPC60 up to a certain extent.

Tab. 5 Modulus of elasticity for the GPC mixes.

\begin{tabular}{ccc}
\hline Mix & Modulus of Elasticity $(\mathrm{GPa})$ & Stiffness $\left(\mathrm{N} / \mathrm{mm}^{2}\right)$ \\
\hline GPC20 & 10.586 & 7676 \\
GPC40 & 14.11 & 15342 \\
GPC60 & 21.212 & 20907 \\
\hline
\end{tabular}

The elastic modulus of the GPC is directly proportional to the compressive strength of the GPC, but the elastic modulus of GPC is comparatively less than the OPC concrete for similar compressive strengths. With an increase in compressive strength from $20 \mathrm{MPa}$ to $40 \mathrm{MPa}$, the modulus of elasticity increased by $33 \%$. With an increase in the compressive strength from $40 \mathrm{MPa}$ to $60 \mathrm{MPa}$, the modulus of elasticity increased by $50 \%$.

An equation is proposed for calculating the modulus of elasticity from the experimental results based on the compressive strength of concrete for the fly ash and GGBS-based geopolymer. The proposed equation shown in Eq. 1 is valid for a compressive strength range of $20 \mathrm{MPa}$ to $60 \mathrm{MPa}$.

$$
\mathrm{E}=\left[4.26 \mathrm{C}^{2}-111.74 \mathrm{C}+10365\right]^{*} 10^{-3} \mathrm{GPa} \quad \text { Eqn. } 1
$$

where $\mathrm{C}=$ compressive strength of GPC
The stiffness increases with an increase in the elastic modulus and compressive strength of the concrete. This might be due to an increase in the volume of the paste, which resulted in the increased homogeneity (a reduction in the voids) of the concrete by improving its compressive strength and stiffness. An increase in GGBS content enhances the compressive strength of concrete while simultaneously increasing the stiffness. With an increase in compressive strength from $20 \mathrm{MPa}$ to $40 \mathrm{MPa}$, the stiffness increases by $100 \%$, and with an increase in compressive strength from $40 \mathrm{MPa}$ to $60 \mathrm{MPa}$, the stiffness increases by $36 \%$.

\section{CONCLUSIONS}

1. An increase in the percentage of GGBS in a mix increases the compressive strength but decreases its workability.

2. The replacement of fly ash with GGBS is found to be a suitable alternative to oven curing.

3. The maximum strain decreases with an increase in the compressive strength of concrete, and the post peak behaviour shifts from ductile to brittle failure.

4. The modulus of elasticity increases with an increase in the compressive strength of concrete, and an equation is proposed for calculating the modulus of elasticity based on the compressive strength of the GPC.

5. The stiffness of the fly ash and GGBS-based geopolymer concrete increases with an increase in the compressive strength.

\section{REFERENCES}

Davidovits J. (2005) Geopolymer, Green Chemistry and Sustainable Development Solutions. Proceedings of the World Congress Geopolymer, Geopolymer Institute.

Duxson, P., Fernandez-Jimenez, A., Provis J.L., Lukey, G.C., Palomo, A., Van Deventer, J.S.J. (2007) Geopolymer technolo$g y$. The current state of the art Journal of Materials Science, Vol. 42, No. 9, pp. 2917-33 doi: 10.1007/s10853-006-0637-z.

Giasuddin, M., Haider, J.G., Sanjayan, P.G., Ranjith (2014) Complete triaxial stress-strain curves for geopolymer. Construction and Building Materials, Vol. 69, pp. 196-202. doi: 10.1016/J.conbuildmat.2014.07.058.

Hardjito, D., Wallah S.E., Sumajouw, D.M., Rangan, B.V. (2004) On the development of fly ash-based geopolymer concrete. American Concrete Institute, Vol. 101, No. 6, pp. 467-72.

IS: 383-1970, Specification for coarse and fine aggregates from natural sources for concrete. Bureau of Indian Standards, New Delhi, India.

IS: 516-1959, Methods of Tests for Strength of Concrete. Bureau of Indian Standards, New Delhi, India.

Khadiraniakar, R.B., Shankar, H., Sanni (2014) Stress Strain Characteristics for Geopolymer Concrete - An Experimental Approach. Current Advances in Civil Engineering, Vol.2, No. 2, pp. 44-47.
Nath, P., Sarker, P.K. (2017) Flexural strength and elastic modulus of ambient-cured blended low-calcium fly ash geopolymer concrete. Construction and Building Materials, Vol. 130, No.3.

Noushini, A., Aslani, F., Castel A., Gilbert R.I, Uy B., Foster S. (2016) Compressive stress-strain model for low-calcium fly ashbased geopolymer and heat-cured Portland cement concrete, Cement Concrete Composites, Vol. 73, No.146.

Rao, G.M., Rao, T.D., Seshu D.R., Venkatesh, A. (2016) Mix proportioning of geopolymer concrete, Cement Wapno Beton, Vol. 21, No. 4., 285pp.

Siddique R. (2007) Waste Materials and By-Products in Concrete. Springer: Verlag Berlin Heideleberg, ISSN: 1612-1317

Thomas, R.J., Peethamparan, S. (2015) Alkali-activated concrete: Engineering properties and stress-strain behaviour. Construction and Building Materials, Vol. 93, No. 56.

Turner L.K., Collins F.G. (2013) Carbon dioxide equivalent (CO2-e) emissions: a comparison between geopolymer and OPC cement concrete. Construction and Building Materials Vol. 43, 125-130 pp. doi.org/10.1016/j.conbuildmat.2013.01.023

Venu, M., Rao, T.D., (2017) Tie-confinement aspects of fly ashGGBS based geopolymer concrete short columns, Construction and Building Materials, Vol. 151, pp. 28-35. doi.org/10.1016/j. conbuildmat.2017.06.065 